\title{
Metastasis Suppressor Gene Raf Kinase Inhibitor Protein (RKIP) Is a Novel Prognostic Marker in Prostate Cancer
}

\author{
Zheng Fu, ${ }^{1}$ Yasuhide Kitagawa, ${ }^{2}$ Ronglai Shen, ${ }^{1}$ Rajal Shah, ${ }^{1}$ Rohit Mehra, ${ }^{1}$ \\ Daniel Rhodes, ${ }^{1}$ Peter J. Keller, ${ }^{1}$ Atsushi Mizokami, ${ }^{2}$ Rodney Dunn, ${ }^{1}$ \\ Arul M. Chinnaiyan, ${ }^{1}$ Zhi Yao, ${ }^{3}$ and Evan T. Keller ${ }^{1 *}$ \\ 'Departments of Urology and Pathology, University of Michigan, Ann Arbor, Michigan \\ ${ }^{2}$ Department of Urology, Kanazawa University, Kanazawa City, Japan \\ ${ }^{3}$ Department of Immunology, Tianjin Medical University, Tianjin, China
}

\begin{abstract}
BACKGROUND. Diminished expression of Raf kinase inhibitor protein (RKIP), an inhibitor of the Raf signaling cascade, promotes prostate cancer (PCa) metastasis in a murine model, suggesting that it is a metastasis suppressor gene. However, the prognostic significance of RKIP expression and its association with metastasis in PCa patients is unknown.

METHODS. To investigate RKIP protein expression is a prognostic marker in PCa we performed immunohistochemical staining for RKIP expression in tissue microarrays consisting of 758 non-neoplastic prostate tissues, primary tumors and metastases from 134 PCa patients. The Cox proportional-hazards model was used to adjust for covariates including Gleason score, tumor volume, tumor weight, clinical stage, digital rectal exam findings, serum PSA level and surgical margins.

RESULTS. RKIP expression was low in approximately 5\%,48\%, and 89\%of non-neoplastic prostate, primary tumors and metastases, respectively. Low RKIP expression in primary tumors was a strong positive predictive factor for PCa recurrence based on PSA levels. In patients whose primary tumors expressed high RKIP levels, the 7-year PSA recurrence rate was $<10 \%$; whereas in patients with tumors with low RKIP expression the recurrence rate was $50 \%$ $(P<0.001)$. Multivariate analysis revealed RKIP was an independent prognostic factor $(P<0.001)$.

CONCLUSION. In contrast to increased expression of pro-tumorigenic genes, these results demonstrate decreased protein expression of a gene, for example, RKIP, can serve as a prognostic marker in PCa patients. Prostate 66: 248-256, 2006. (C) 2005 Wiley-Liss, Inc.
\end{abstract}

KEY WORDS: $\quad$ prognostic marker; RKIP; prostate cancer; metastasis suppressor gene; tissue microarray

\section{INTRODUCTION}

Prostate cancer (PCa) metastases are the leading cause of cancer-related death among American men [1]. A major challenge of treating PCa lies in accurately distinguishing those histologically localized cancers, which will undergo metastasis from those that will remain indolent. Although there are abundant clinicopathological data regarding $\mathrm{PCa}$, these data are deficient in their utility to help predict the likelihood
Grant sponsor: National Cancer Institute; Grant number: R01CA098513; Grant sponsor: SPORE; Grant number: 1 P50 CA69568.

*Correspondence to: Evan T. Keller, Room 5304, CCGC building, 500 E. Medical Center Dr., University of Michigan, Ann Arbor, MI 481090940. E-mail: etkeller@umich.edu.

Received 10 April 2005; Accepted 8 June 2005

DOI 10.1002/pros.20319

Published online 20 September 2005 in Wiley InterScience (www.interscience.wiley.com). 
of cancer recurrence as evidenced by the observation that $20 \%-30 \%$ of resected PCas recur although they are theoretically curable based on prognostic factors [2,3]. The heterogeneity of $\mathrm{CaP}$ and its variable response to treatment account for the dearth of prognostic markers that can distinguish between tumors with high versus low recurrence potential [4]. In order to improve the ability to accurately predict which patients have the greatest risk for developing aggressive $\mathrm{PCa}$, the search for new biochemical markers that are capable of predicting PCa prognosis and, thus offer the opportunity to provide optimal care for each PCa patient is of great demand.

In a search for genes that regulate the metastatic process in $\mathrm{PCa}$, we performed gene array analysis between non-metastatic and metastatic PCa cell lines. This analysis revealed that Raf kinase inhibitor protein (RKIP) expression was decreased in the metastatic compared to non-metastatic cell line [5]. RKIP is a soluble 23-kDa basic cytosolic protein that was initially characterized as phosphatidylethanolamine-binding protein (PEBP) [6,7]. RKIP suppresses mitogenactivated protein kinase signaling by binding to Raf-1 and disrupting the physical interaction between Raf-1 and MEK [8]. In addition to its inhibition of Raf-1mediated activity, RKIP inhibits activation of both the transcription factor nuclear factor kappa B (NF- $\mathrm{B}$ ) [9] and G-coupled protein kinase 3 [10]. We previously demonstrated that RKIP fits the criteria of a PCa metastasis suppressor gene (MSG) including the ability to inhibit metastasis without an effect on primary tumor growth in a murine model [11]. Taken together, these observations suggest that RKIP has potential as a molecular determinant of PCa progression and metastasis and thus provide a prognostic value in PCa.

In this study, we utilized tissue microarrays to evaluate the expression of RKIP protein in a wide spectrum of prostate tissues in order to determine comprehensively the extent and patterns of its expression in situ. In addition, with the aid of welldocumented clinical information for those patients we evaluated the prognostic value of RKIP in PCa.

\section{MATERIALS AND METHODS}

\section{Microarray Analysis From Meta-Analysis of Oncomine Database}

The expression RKIP transcript in cancer tissues was obtained from meta-analysis of our recently established cancer gene microarray meta-analysis public database [12]. The normalized expression unit for RKIP transcript was exported and subjected to statistical analysis as previously described [12].

\section{Case Selection and Tissue Microarrays}

Cases of clinically localized PCa were identified from a radical prostatectomy series at the University of Michigan and cases with PCa metastases were obtained from a Rapid Autopsy Program through the Michigan Prostate SPORE Tissue Core (Table I). The autopsy protocol and initial characterization of these cases have recently reported [13]. Briefly, all the patients had welldocumented metastatic PCa. Autopsies were performed within 4-6 hr of the patient's death. Autopsy revealed widespread PCa involving multiple sites. No other primary malignancy was found. All tissue procurement and analysis in this study was approved by Institutional Review Board approval to procure and analyze the tissues used. Standard demographic and treatment history parameters were recorded.

To study the expression of RKIP in PCa, we used two tissue microarrays (TMAs) that consisted of a total of 758 evaluable samples of non-neoplastic prostate $(\mathrm{n}=57)$, localized PCa $(\mathrm{n}=79)$ and metastatic, hormone-refractory PCa $(\mathrm{n}=55)$. All 79 patients with localized PCa underwent prostatectomy to treat their localized disease. Gleason scores were 5 in 3 cases, 6 in 28 cases, 7 in 45 cases, and 8 in 3 cases. The metastatic TMAs included PCa metastatic to the liver, lung, bone, lymph node, brain, adrenal, and soft tissue. At least six 0.6-mm cores were taken from each sample. Highdensity TMAs were assembled as previously described $[14,15]$. Initial sections were stained for hematoxylin and eosin to verify histology. The histological grade was assessed using the Gleason grading system according to previously described methods [16]. Clinical and pathological variables were determined following well-established criteria and maintained in a secure relational database as previously described [17].

\section{Immunohistochemistry and Evaluation}

Standard avidin-biotin complex immunohistochemistry (IHC) was used. Briefly, antigen retrieval was performed by steaming the slides for $15 \mathrm{~min}$ in $10 \mathrm{mM}$ sodium citrate buffer, $\mathrm{pH} 6.0$, in a microwave oven. The slides were then incubated sequentially with primary antibody, biotinylated secondary antibody, avidinbiotin complex, and chromogenic substrate 3, 3'diaminobenzidine. RKIP protein was detected using a rabbit polyclonal anti-RKIP antibody (1:600 dilution, Upstate Biotechnology, Lake Placid, NY). RKIP staining intensity was independently scored by two genitourinary pathologists blinded to Gleason score, tumor size, and clinical outcome. The staining was scored as previously described [11,14]. Briefly, immunostaining intensity was scored by a genito-urinary pathologist as negative [1], weak [2], moderate [3], or strong [4] based on the amount of stain detected. The 
TABLE I. Clinical Characteristics of 79 Patients Whose Resected Prostate Cancers Were Evlauted for RKIP Expression ${ }^{\mathrm{a}}$

\begin{tabular}{|c|c|c|c|c|}
\hline Characteristic & Total & RKIP moderate/high & RKIP negative/low & $P$-value \\
\hline Age (year) & $60.3 \pm 7.7^{\mathrm{b}}$ & $60.2 \pm 7.4$ & $60.4 \pm 8.0$ & $0.91^{\mathrm{c}}$ \\
\hline \multicolumn{5}{|l|}{ Race } \\
\hline Caucasian & $52(66)$ & $27(66)$ & $25(66)$ & \multirow[t]{3}{*}{$0.77^{\mathrm{d}}$} \\
\hline African-American & $19(24)$ & $9(22)$ & $10(26)$ & \\
\hline Other & $8(10)$ & $5(12)$ & $3(8)$ & \\
\hline Length of follow-up (month) & $50.0 \pm 28.5$ & $59.9 \pm 22.0$ & $39.3 \pm 30.9$ & $0.0009^{\mathrm{a}}$ \\
\hline Pre-prostatectomy PSA (ng/mL ) & $9.0 \pm 8.8$ & $8.7 \pm 7.7$ & $9.3 \pm 9.9$ & $0.76^{\mathrm{a}}$ \\
\hline Maximum tumor diameter $(\mathrm{cm})$ & $1.6 \pm 0.7$ & $1.6 \pm 0.7$ & $1.5 \pm 0.6$ & $0.40^{\mathrm{a}}$ \\
\hline Gland weight $(\mathrm{g})$ & $51.8 \pm 16.6$ & $53.7 \pm 19.3$ & $49.8 \pm 13$ & $0.29^{\mathrm{a}}$ \\
\hline \multicolumn{5}{|l|}{ Gleason score-no. (\%) } \\
\hline 5 & $3(4)$ & $2(5)$ & $1(3)$ & \multirow[t]{4}{*}{$0.08^{\mathrm{e}}$} \\
\hline 6 & $28(35)$ & $19(46)$ & $9(24)$ & \\
\hline 7 & $45(57)$ & $18(44)$ & $27(71)$ & \\
\hline 8 & $3(4)$ & $2(5)$ & $1(3)$ & \\
\hline \multicolumn{5}{|l|}{ DRE } \\
\hline Negative-no. (\%) & $49(62)$ & $27(66)$ & $22(28)$ & \multirow[t]{2}{*}{$0.47^{\mathrm{d}}$} \\
\hline Positive-no. (\%) & $30(38)$ & $14(34)$ & $16(42)$ & \\
\hline \multicolumn{5}{|l|}{ Pathologic stage-no. (\%) } \\
\hline pT2 & $60(76)$ & $35(85)$ & $25(66)$ & \multirow[t]{2}{*}{$0.04^{\mathrm{d}}$} \\
\hline pT3 & $19(24)$ & $6(15)$ & $13(34)$ & \\
\hline \multicolumn{5}{|l|}{ Surgical margin status } \\
\hline Negative-no. (\%) & $53(67)$ & $31(76)$ & $22(58)$ & \multirow[t]{2}{*}{$0.09^{\mathrm{d}}$} \\
\hline Positive-no. (\%) & $26(33)$ & $10(24)$ & $16(42)$ & \\
\hline \multicolumn{5}{|l|}{ PSA-defined recurrence } \\
\hline No-no. $(\%)$ & $58(73)$ & $36(88)$ & $22(58)$ & \multirow[t]{2}{*}{$0.003^{\mathrm{d}}$} \\
\hline Yes-no. $(\%)$ & $21(27)$ & $5(12)$ & $16(42)$ & \\
\hline
\end{tabular}

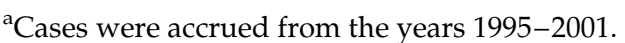

${ }^{\mathrm{b}}$ Data are presented as mean $\pm \mathrm{SD}$.

'The $P$-value was calculated by Wilcoxon's rank-sum test for the comparison of the RKIP moderate/high group with the RKIP negative/ low group.

${ }^{\mathrm{d}}$ The $P$-value was calculated by the Student's $t$-test for the comparison of the RKIP moderate/high group with the RKIP negative/ low group.

'The $P$-value was calculated by the Fisher's exact test for the comparison of the RKIP moderate/high group with the RKIP negative/ low group.

PSA, prostate specific antigen; DRE, digital rectal examination.

pathologist evaluated the spectrum of staining intensity in all the samples and then arbitrarily categorizes the staining intensity into the various scores based on the overall staining. The pathologist was blinded to Gleason score, tumor size, or clinical outcome. On average, four tissue cores were evaluated from each case and the median value of all measurements from a single case was used as the final score for subsequent analysis. A total of 758 samples from non-neoplastic tissue $(n=57)$, localized PCa $(n=79)$, and metastatic PCa $(n=55)$ were examined.

\section{Statistical Analysis}

For analysis of gene microarray data, Student's $t$-test was used for pair-wise comparison of RKIP transcript among benign prostate, localized PCa and metastatic PCa samples as previously described [18].

For statistical evaluation of immunohistochemistry staining, RKIP staining was dichotomized into high (Median RKIP staining $\geq 3$ ) and low (median $\leq 2$ ) categories. The Mantel-Haenszel chi-square test was applied to compare the RKIP staining in non-neoplastic prostate, $\mathrm{PCa}$, and metastases. This was followed by chi-square test for post-hoc analysis. A $P$-value of $<0.05$ was considered significant. PSA recurrence was calculated from the date of surgical excision of the primary tumor to the date of recurrence or the end of follow-up. Kaplan-Meier analysis and Cox regression models were applied to evaluate the predictive values of RKIP and clinical parameters in differentiating recurrence outcome. Statistical significance in the Cox models was determined by the log-rank test. 


\section{RESULTS}

Analysis of gene expression data sets from our recently established cancer gene microarray metaanalysis public database [12] demonstrated decreased RKIP expression with advanced cancer. Specifically, Dhanasekaran et al. [18] investigated gene expression patterns in non-cancerous prostate, localized $\mathrm{PCa}$, and metastatic PCa (Fig. 1). Our analysis of this dataset revealed that RKIP mRNA expression was significantly lower in localized PCa than that in non-cancerous prostate samples $(P=0.003$, Student's $t$-test $)$. Furthermore, metastatic PCa has statistically significantly lower RKIP mRNA expression relative to both noncancerous prostate tissues $(P<0.001$, Student's $t$-test) and localized PCa ( $\mathrm{P}=0.021$, Student's $t$-test) (Fig. 1). These data are in agreement with our previous findings in PCa cell lines [11] and demonstrate that RKIP mRNA expression declines with PCa progression.

To determine if changes in mRNA expression were reflected by protein expression, we performed immunohistochemistry for RKIP protein expression on previously validated PCa tissue microarrays [13,14]. For benign prostate samples, the men had a mean age of 58 years (range: $45-80$ ). The patient demographics for the men with primary tumors are described in detail in Table I. For men with metastatic cancer, pre-prostatectomy data were unavailable; however, in summary there were 55 men with metastases with a mean age of 67 years (range: 40-84 years) approximately 36\% had



Fig. I. RKIP $m R N A$ transcript levels is decreased in prostate cancer (PCa). RKIP mRNA transcript levels in PCa progression measured using DNA microarrays as reported by Dhanasekaran et al. [18]. There were 22 cases of benign prostate, 59 cases of localized $\mathrm{PCa}, 20$ cases of metastatic PCa included in the study. Y-axis represents normalized expression units. $P$-value was calculated by using the Student's t test. prostatectomy; $60 \%$ had bilateral orchiectomy; $5 \%$ had radiation therapy; and $100 \%$ had chemotherapy and hormone ablation. PCa metastases that were examined included skeletal, lymph node, hepatic, pulmonary, dural, adrenal, splenic, spine, diaphragmatic, bladder, seminal vesicle, testis, and pancreatic metastases. RKIP protein staining was cytoplasmic in all positive cases (Fig. 2A,B). The prostatic origin of tumor cells expressing RKIP was confirmed by positive IHC staining for PSA (not shown). The intensity of RKIP staining was dichotomized into two groups; weak/negative staining (score of 1 or 2) and moderate/strong staining (score of 3 or 4 ). IHC analysis revealed that $95 \%$ of the non-neoplastic prostate samples had moderate/strong staining; whereas only $5 \%$ had negative/weak staining. This differed for primary tumors of which $52 \%$ had moderate/strong staining and $48 \%$ had negative/weak staining. Finally, only $11 \%$ of the metastatic tumors had moderate/strong staining; whereas, $89 \%$ had negative/weak staining (Fig. 2C). These data clearly demonstrate that RKIP protein expression decreases with overall PCa progression $(P<0.0001$, MantelHaenszel chi-square test). Furthermore, there was a significant decrease in RKIP staining intensity between benign prostate tissue compared to primary tumor tissue ( $P<0.0001$, chi-square test). Similarly, metastatic PCa had significantly lower expression of RKIP than did clinically localized PCa $(P<0.0001$, chi-square test). These data suggest that RKIP expression could be used to indicate the aggressiveness of an individual's PCa. To further confirm that the there was a difference in RKIP expression between benign prostate and primary tumors we identified those patients in which we had paired benign tissue and primary tumors. There were 38 patients with paired benign prostate and primary tumors. The mean RKIP staining was decreased in the primary tumors (mean $=2.9 \pm$ 0.37 ) compared to benign prostate tissues (mean $=$ $3.9 \pm 0.32 ; P<0.001)$.

To begin to explore the prognostic utility of RKIP expression in primary tumors, we initially evaluated the association of RKIP protein expression with clinical and pathological parameters. The clinical and pathologic characteristics of the men with primary tumors are shown in Table I. The mean age of the study population was 60 years $( \pm 7.7)$. After a mean follow-up of 50.0 months ( \pm 28.5$), 21$ of the 79 patients $(27 \%)$ had PSA recurrence. The 5- and 7-year disease-specific survival rates for the entire cohort of patients were $72.8 \%$ $( \pm 5.26 \%)$ and $69.6 \%( \pm 5.91 \%)$, respectively. Clinical stage was dichotomized by results of the digital rectal examination (DRE) into palpable (or positive) and nonpalpable (or negative) groups. Pathological stage was simplified to two classes, pT2 (organ-confined) and pT3 (extraprostatic extension and/or seminal vesicle 
A

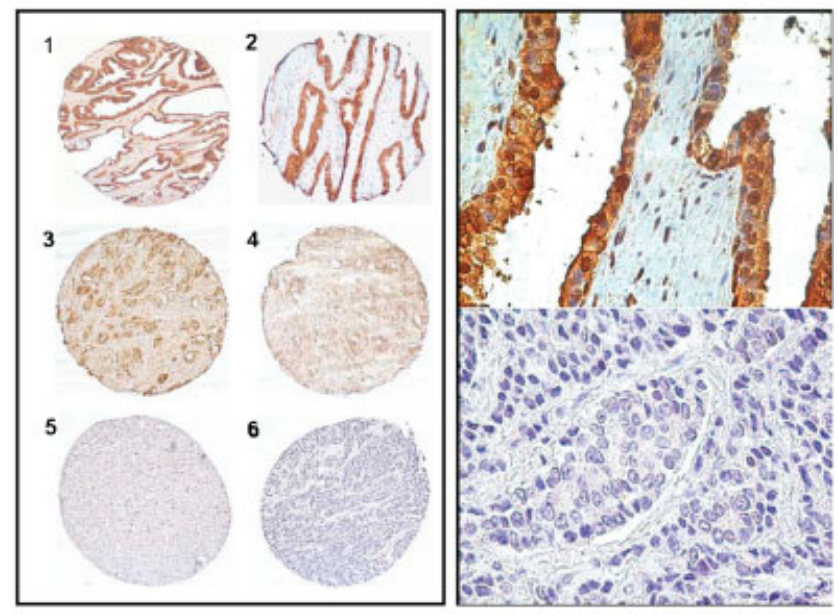

C

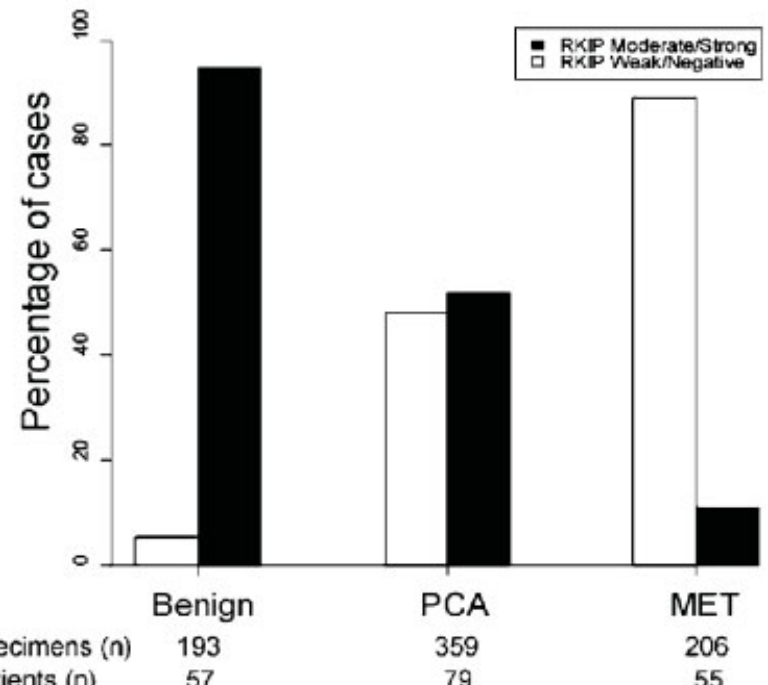

Fig. 2. RKIP protein is downregulated in PCa. (A) Representative elements of a tissue microarray stained with anti-RKIP antibody. Immunohistochemistry demonstrates strong staining of non-neoplastic prostate (AI-2), moderate staining in localized PCa (A3-4), and absent or weak staining of metastatic $\mathrm{PCa}(\mathrm{A} 5$ - 6). Magnification $100 \times$. (B) RKIP expression is high in the secretary luminal cells of non-neoplastic prostate (top), but absent in metastatic PCa (bottom). Magnification $400 \times$. (C) Histogram of RKIP expression by tissue type based on tissue microarray analysis. Tumor specimens were stratified into high RKIP expression (filled bars, score 3 or 4 ) and low RKIP expression (open bars, scored I or 2). They-axis represents the percentage of patients in each category. RKIP expression decreases with increasing progression $(P<0.000$, Mantel-Haenszel chisquare test). RKIP expression differs between all pairwise comparisons $(P<0.000$ l, chi-square analysis).

invasion). The natural logarithm of the preoperative level of PSA (ln [PSA]) was used as previously described [18]. RKIP showed the strongest association with length of follow-up $(P=0.0009)$ and PSA recurrence rate (0.003) (Table I). Specifically, RKIP levels were inversely correlated with them, such that patients with lower RKIP levels had earlier recurrence and higher recurrence rate than those with higher RKIP expression. Additionally RKIP expression was inversely correlated with pathological stage $(P=0.04)$, whereas Gleason score were marginally associated with RKIP levels. There was no significant correlation between RKIP expression level and surgical margin (SM) status $(P=0.09)$, tumor size $(P=0.40)$, gland weight $(P=$ $0.28)$, ln $[P S A](P=0.59)$ or clinical stage $(P=0.47)$.

PSA failure (also termed PSA recurrence or biochemical relapse) is defined as developing elevated PSA levels greater than $0.2 \mathrm{ng} / \mathrm{ml}$ after radical prostatectomy [19]. Patients demonstrating PSA failure typically progress to developing distant metastases and dying of PCa [19]. To test whether RKIP can be used as a potential PCa biomarker to predict clinical outcome in men treated with prostatectomy for clinically localized PCa, we performed outcome analysis on 359 prostate samples from the 79 men with localized PCa (each patient's tumor is evaluated with an average of 4 samples). Kaplan-Meier analysis (Fig. 3A) revealed that negative/weak RKIP staining predicted an earlier PSA recurrence than moderate/strong RKIP expression. At 7 years of follow-up, only $13 \%$ of the patients with moderate/strong staining tumors had PSA recurrence, compared to $48 \%$ of the patients with negative/weak staining tumors $(P<0.001, \log$ rank). These data demonstrate that RKIP expression is prognostic for PSA recurrence.

To explore what clinical and pathological parameters could predict early PSA recurrence, we initially performed a univariate analysis (Table II). At the univariate level, tumor diameter, pathological stage, SM status and ln [PSA] were directly associated with PSA recurrence. In contrast, RKIP protein expression was inversely associated with PSA recurrence. Gland weight, Gleason score, and clinical stage were not associated with PSA recurrence.

To examine the prognostic value of RKIP expression independent of known clinical and pathologic parameters, multivariate analysis was performed (Table II). To fit a multivariable Cox hazards regression model, RKIP expression level along with tumor diameter, pathological stage, SM status, In [PSA], gland weight, Gleason score, and clinical stage were included in the model. The analysis indicated that RKIP expression was the most significant predictor of PSA recurrence followed by SM status and ln [PSA] (Table II). As in the univariate analysis, RKIP was inversely correlated with PSA recurrence and SM status and ln [PSA] were directly correlated with PSA recurrence. Although tumor size and pathologic stage had a strong association with PSA recurrence at the univariate level, they had no independent association with outcome at the 
multivariate level. A multivariate analysis of only the three independent factors revealed that RKIP maintained significance as an independent factor, giving a final best fit multivariate model predictive of PSA

A

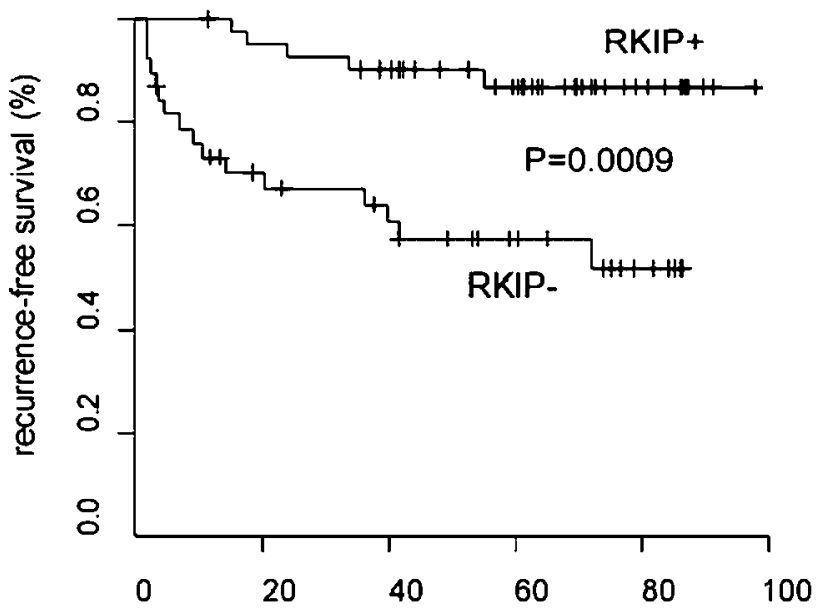

Months after surgery

\begin{tabular}{lcccc}
\multicolumn{4}{c}{5 All $(n=79)$} & \multicolumn{2}{c}{7 yrs } \\
\hline & $\begin{array}{c}\text { survival rate } \\
(95 \% \text { Cl })\end{array}$ & Number at risk & $\begin{array}{c}\text { survival rate } \\
(95 \% \text { Cl) }\end{array}$ & Number at risk \\
\hline RKIP+ & $0.87(0.76,0.98)$ & 27 & $0.87(0.76,0.98)$ & 27 \\
RKIP. & $0.57(0.43,0.77)$ & 18 & $0.52(0.36,0.74)$ & 10 \\
\hline
\end{tabular}

B

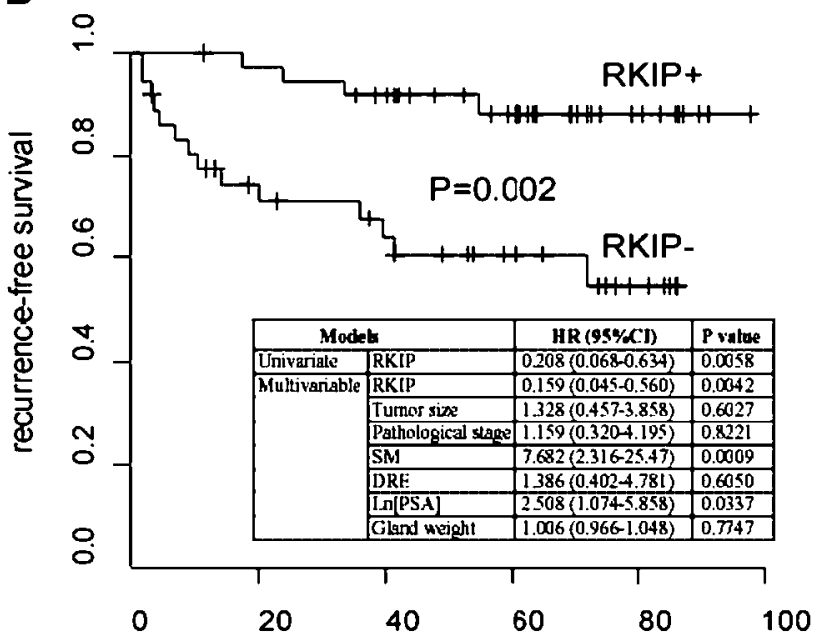

Months after surgery

\begin{tabular}{|c|c|c|c|c|}
\hline \multicolumn{5}{|c|}{ Gleason=6+7 $(n=73)$} \\
\hline & \multicolumn{2}{|c|}{5 yis } & \multicolumn{2}{|c|}{7 yrs } \\
\hline & $\begin{array}{c}\text { sunival rate } \\
\text { (95\% c) }\end{array}$ & Number at risk & $\begin{array}{c}\text { sunival rate } \\
\text { (95\% CD) }\end{array}$ & Number at risk \\
\hline RKIP+ & $0.88(0.77,1.00)$ & 24 & $0.88(0.77,1.00)$ & 24 \\
\hline RKIP. & $0.61(0.46,0.80)$ & 18 & $0.56(0.38,0.77)$ & 10 \\
\hline
\end{tabular}

recurrence that included the following terms and their hazard ratios $(95 \% \mathrm{CI}$; all at $P=0.0005$, Cox regression analysis): RKIP expression, $0.15,(0.05-0.44) ; \ln$ [PSA], 6.73 (2.62-17.32) and surgical margin status 3.15 (1.685.88). Based on this model, patients with a negative/ low RKIP expression are $85 \%$ more likely to have an early PSA recurrence compared to those with moderate/high RKIP expression. These results demonstrate that expression of a MSG, namely RKIP, adds considerably to a prognostic model for PSA recurrence.

The majority of $\mathrm{CaP}$ patients who undergo prostatectomy have intermediate Gleason scores (i.e., scores of 6-7) $[20,21]$. These Gleason scores are fairly noninformative as it is difficult to determine prognosis of patients that have tumors with these Gleason scores [20-22]. Accordingly, to determine if RKIP expression could provide additional prognostic information for this subset of patients, we performed multivariate Cox regression analysis of patients with Gleason scores 6 or 7 using clinical and pathological parameters. RKIP level is a significantly better marker than $\ln$ [PSA] and an as good a marker as surgical margin status (Fig. 3B). Patients with tumors with Gleason score of 6 or 7 and negative/low RKIP expression have a $79.2 \%$ greater chance of PSA recurrence than those patients with tumors that have moderate/high RKIP expression. These results indicate that RKIP is a novel excellent predictor of PSA recurrence in CaP patients with Gleason scores of 6 and 7 and can provide greater prognostic information than that of the currently used Gleason score in this class of patients.

\section{DISCUSSION}

Our results demonstrate that RKIP expression is decreased in PCa metastases and that immunohistochemical assessment of RKIP in primary $\mathrm{CaP}$ provides important independent prognostic information. Specifically, in patients with tumors that express moderate/ high RKIP levels, the time to PSA recurrence is significantly delayed compared to patients with tumor that have negative/low RKIP expression. Approximately $50 \%$ of the patients' primary tumors we examined expressed negative/low RKIP levels, thus indicating that these patients represent a significant component of the $\mathrm{PCa}$ population undergoing

Fig. 3. Kaplan-Meier estimates of PSA recurrence-free probability for the patients with clinically localized PCa. (A) All patients: Patients were stratified on the basis of moderate/high (RKIP+) or negative/low (RKIP-) RKIPexpression levels. $P$-value was calculated using the log-rank test. (B) Patients with Gleason score 6 or 7 tumors: Patients were stratified on the basis of moderate/high (RKIP + ) or negative/low (RKIP-) RKIP expression levels. P-value was calculated using the log-rank test. 
TABLE II. Univariate and Multivariable COX Hazards Analysis of Clinicopathological Parameters and Rkip Expression in 79 Patients With Prostate Cancer*

\begin{tabular}{|c|c|c|c|c|}
\hline \multirow[b]{2}{*}{ Variable } & \multicolumn{2}{|c|}{ Univariate analysis } & \multicolumn{2}{|c|}{ Multivariate analysis } \\
\hline & $\operatorname{HR}(95 \% \mathrm{CI})$ & $P$-value ${ }^{\mathrm{a}}$ & $\operatorname{HR}(95 \% \mathrm{CI})$ & $P$-value ${ }^{\mathrm{a}}$ \\
\hline RKIP & $0.21(0.08-0.58)$ & 0.002 & $0.11(0.03-0.38)$ & 0.0005 \\
\hline Gleason score & $1.80(0.70-4.63)$ & 0.23 & $0.38(0.12-1.20)$ & 0.10 \\
\hline Maximal tumor diameter & $3.15(1.34-7.42)$ & 0.009 & $1.29(0.46-3.60)$ & 0.63 \\
\hline Pathological stage & $3.70(1.57-8.74)$ & 0.003 & $1.33(0.36-4.88)$ & 0.66 \\
\hline SM & $6.34(2.54-15.80)$ & $<0.0001$ & $6.72(2.21-20.49)$ & 0.0008 \\
\hline DRE & $1.66(0.71-3.91)$ & 0.25 & $1.48(0.43-5.07)$ & 0.53 \\
\hline $\ln [\mathrm{PSA}]$ & $2.46(1.39-4.36)$ & 0.002 & $2.91(1.33-6.37)$ & 0.007 \\
\hline Gland weight & $0.99(0.96-1.02)$ & 0.45 & $1.00(0.96-1.03)$ & 0.93 \\
\hline
\end{tabular}

${ }^{*} \mathrm{HR}$, hazard ratio; CI, confidence interval; SM, surgical margin status; ln [PSA], natural logarithm of the pretreatment prostate-specific antigen level ( $\mathrm{ng} / \mathrm{mL})$.

${ }^{\mathrm{a} C o x}$ regression analysis. All statistical tests were two-sided.

prostatectomy. In our study cohort, the only other independent prognostic indicators that we found were surgical margins and $\ln$ [PSA].

A variety of MSGs has been evaluated for prognosis in multiple cancers. However, until the current study, there has been no clear documentation that decreased expression of a MSG is prognostic for a cancer. For example, the MSG KAI1 was demonstrated not to be an independent prognostic factor in endometrial cancer [23], cervical cancer [24], or ovarian carcinoma [25]. In fact, increased, as opposed to decreased, levels of a KAI1 splice variant was shown to be an a poor prognostic factor in gastric cancer [26]. Similarly, increased expression of other MSGs KiSS-1 and nm23 have been shown to indicate a poor prognosis several cancers [27-30] or as with the MSG CD44 not to predict outcome in cancer[31]; although in one study CD44 was shown to predict survival [32]. In summary, decreased expression of MSGs has not been clearly demonstrated to be prognostic. Thus, our report provides an initial example of a MSG involved in intracellular signaling that is prognostic for cancer recurrence, which demonstrates the importance of evaluating genes that have decreased expression for prognostic value.

Currently used markers for prognosis of PCa such as preoperative serum PSA level, tumor stage, tumor grade as measured by the Gleason score and surgical margin are limited in their accuracy and prognostic ability (reviewed in 33). For example, PSA screening may in lead to the overdiagnosis and overtreatment of patients with PCa [34]. In addition, PSA does not correlate well with clinical outcome in patients with PSA values of $<10 \mathrm{ng} / \mathrm{mL}$ [35]. Similarly, the most commonly used grading system in PCa, Gleason score [36,37], is most effective as a prognostic factor in tumors with the low [2-4] or high [8-10] scores, but not very effective in the more common tumors that have an intermediate score [5-7] and show strikingly heterogeneous biological aggressiveness $[33,38]$. Thus development of additional prognostic markers is an important area of research. Results from the current study demonstrate that RKIP is prognostic in patients with PSA $<10 \mathrm{ng} / \mathrm{ml}$ and with tumors that are Gleason score $6-7$ or have positive surgical margins. Thus, RKIP offers prognostic benefits above and beyond PSA, Gleason score, and adds further information to those tumors with positive surgical margins.

Radical prostatectomy is a definitive form of therapy for clinically localized PCa [39]. After radical prostatectomy, recurrence of the disease in men with negative surgical margin suggests that undetected disease may have spread beyond the prostate gland before surgery $[40,41]$. Detecting this population of patients would assist towards designing a therapeutic strategy, including aggressive treatment. Our data demonstrate that tumor RKIP expression levels can be used to predict which of these patients will have early PSA recurrence, and thus be used to provide a therapeutic recommendation. It is worth noting that traditional Gleason score did not statistically significantly stratify the risk of this focused set of patients although its clinical implication on prognostication has been demonstrated by many groups $[42,43]$. We believe this was due to the fact that the majority of the patients in this study had intermediate Gleason scores (6 and 7) and intermediate Gleason score is least sensitive prognostic marker to stratify high risk patients [20-22].

Our finding that RKIP protein expression level in PCa provides independent prognostic information, given the novel metastasis suppressor activity of RKIP in $\mathrm{PCa}$, underscores that determining pathophysiological mechanisms of cancer spread can lead to 
identification of molecular markers. These findings should be tempered by the observation that there is overlap of RKIP mRNA expression among normal, primary tumors and metastases, which suggests that RKIP mRNA expression may have limited use as a sole prognostic factors in individuals; however, the data indicate that low RKIP protein expression provides a strong indication of early PSA failure. Accordingly, assessment of RKIP expression may identify those patients that could benefit from early aggressive therapy.

\section{ACKNOWLEDGMENTS}

This work was supported by National Cancer Institute Grants R01-CA098513 (to E.T.K.) and SPORE 1 P50 CA69568 (to E.T.K).

\section{REFERENCES}

1. Landis SH, Murray T, Bolden S, Wingo PA. Cancer statistics. CA Cancer J Clin 1998;48(1):6-29.

2. Lerner SP, Seale-Hawkins C, Carlton CE Jr, Scardino PT. The risk of dying of prostate cancer in patients with clinically localized disease. J Urol 1991;146(4):1040-1045.

3. Schellhammer PF. Radical prostatectomy. Patterns of local failure and survival in 67 patients. Urology 1988;31(3):191-197.

4. Roberts WW, Bergstralh EJ, Blute ML, Slezak JM, Carducci M, Han M, Epstein JI, Eisenberger MA, Walsh PC, Partin AW. Contemporary identification of patients at high risk of early prostate cancer recurrence after radical retropubic prostatectomy. Urology 2001;57(6):1033-1037.

5. Fu Z, Dozmorov I, Keller E. Osteoblasts produce soluble factors that induce a gene expression pattern in non-metastatic prostate cancer cells, similar to that found in bone metastatic prostate cancer cells. Prostate 2002;51:10-20.

6. Perry AC, Hall L, Bell AE, Jones R. Sequence analysis of a mammalian phospholipid-binding protein from testis and epididymis and its distribution between spermatozoa and extracellular secretions. Biochem J 1994;301(Pt 1):235-242.

7. Tohdoh N, Tojo S, Agui H, Ojika K. Sequence homology of rat and human HCNP precursor proteins, bovine phosphatidylethanolamine-binding protein and rat $23-\mathrm{kDa}$ protein associated with the opioid-binding protein. Brain Res Mol Brain Res 1995;30(2):381-384.

8. Yeung K, Seitz T, Li S, Janosch P, McFerran B, Kaiser C, Fee F, Katsanakis KD, Rose DW, Mischak H, Sedivy JM, Kolch W. Suppression of Raf-1 kinase activity and MAP kinase signalling by RKIP. Nature 1999;401(6749):173-177.

9. Yeung KC, Rose DW, Dhillon AS, Yaros D, Gustafsson M, Chatterjee D, McFerran B, Wyche J, Kolch W, Sedivy JM. Raf kinase inhibitor protein interacts with NF-kappaB-inducing kinase and TAK1 and inhibits NF-kappaB activation. Mol Cell Biol 2001;21(21):7207-7217.

10. Lorenz K, Lohse MJ, Quitterer U. Protein kinase C switches the Raf kinase inhibitor from Raf-1 to GRK-2. Nature 2003; 426(6966):574-579.

11. Fu Z, Smith PC, Zhang L, Rubin MA, Dunn RL, Yao Z, Keller ET. Effects of raf kinase inhibitor protein expression on suppression of prostate cancer metastasis. J Natl Cancer Inst 2003;95(12): 878-889.
12. Rhodes DR, Yu J, Shanker K, Deshpande N, Varambally R, Ghosh D, Barrette TR, Pandey A, Chinnaiyan AM. Oncomine: A cancer microarray database and integrated data-mining platform. Neoplasia 2004;6(1):1-6.

13. Rubin MA, Putzi M, Mucci N, Smith DC, Wojno K, KorenchukS, Pienta KJ. Rapid ("warm") autopsy study for procurement of metastatic prostate cancer. Clin Cancer Res 2000;6(3):1038-1045.

14. Perrone EE, Theoharis C, Mucci NR, Hayasaka S, Taylor JM, Cooney KA, Rubin MA. Tissue microarray assessment of prostate cancer tumor proliferation in African- American and white men. J Natl Cancer Inst 2000;92(11):937-939.

15. Kononen J, Bubendorf L, Kallioniemi A, Barlund M, Schraml P, Leighton S, Torhorst J, Mihatsch MJ, Sauter G, Kallioniemi OP. Tissue microarrays for high-throughput molecular profiling of tumor specimens. Nat Med 1998;4(7):844-847.

16. Gleason DF. Classification of prostatic carcinomas. Cancer Chemother Rep 1966;50(3):125-128.

17. Manley S, Mucci NR, De Marzo AM, Rubin MA. Relational database structure to manage high-density tissue microarray data and images for pathology studies focusing on clinical outcome: The prostate specialized program of research excellence model. Am J Pathol 2001;159(3):837-843.

18. Dhanasekaran SM, Barrette TR, Ghosh D, Shah R, Varambally S, Kurachi K, Pienta KJ, Rubin MA, Chinnaiyan AM. Delineation of prognostic biomarkers in prostate cancer. Nature 2001; 412(6849):822-826.

19. Pound CR, Partin AW, Eisenberger MA, Chan DW, Pearson JD, Walsh PC. Natural history of progression after PSA elevation following radical prostatectomy. Jama 1999;281(17):1591-1597.

20. Ayala G, Tuxhorn JA, Wheeler TM, Frolov A, Scardino PT, Ohori M, Wheeler M, Spitler J, Rowley DR. Reactive stroma as a predictor of biochemical-free recurrence in prostate cancer. Clin Cancer Res 2003;9(13):4792-4801.

21. Ayala G, Wang D, Wulf G, Frolov A, Li R, Sowadski J, Wheeler TM, Lu KP, Bao L. The prolyl isomerase Pin1 is a novel prognostic marker in human prostate cancer. Cancer Res 2003; 63(19):6244-6251.

22. Dash A, Sanda MG, Yu M, Taylor JM, Fecko A, Rubin MA. Prostate cancer involving the bladder neck: Recurrence-free survival and implications for AJCC staging modification. American Joint Committee on Cancer. Urology 2002;60(2):276-280.

23. Liu FS, Dong JT, Chen JT, Hsieh YT, Ho ES, Hung MJ, Lu CH, Chiou LC. KAI1 metastasis suppressor protein is downregulated during the progression of human endometrial cancer. Clin Cancer Res 2003;9(4):1393-1398.

24. Schindl M, Birner P, Bachtiary B, Breitenecker G, Selzer E, Oberhuber G. The impact of expression of the metastasis suppressor protein KAI1 on prognosis in invasive squamous cell cervical cancer. Anticancer Res 2000;20(6B):4551-4555.

25. Liu FS, Dong JT, Chen JT, Hsieh YT, Ho ES, Hung MJ. Frequent down-regulation and lack of mutation of the KAI1 metastasis suppressor gene in epithelial ovarian carcinoma. Gynecol Oncol 2000;78(1):10-15.

26. Lee JH, Seo YW, Park SR, Kim YJ, Kim KK. Expression of a splice variant of KAI1, a tumor metastasis suppressor gene, influences tumor invasion and progression. Cancer Res 2003;63(21):72477255 .

27. Ikeguchi M, Hirooka Y, Kaibara N. Quantitative reverse transcriptase polymerase chain reaction analysis for KiSS-1 and orphan G-protein-coupled receptor (hOT7T175) gene expression in hepatocellular carcinoma. J Cancer Res Clin Oncol 2003;129(9):531-535. 
28. Niitsu N, Honma Y, Iijima K, Takagi T, Higashihara M, Sawada $\mathrm{U}$, Okabe-Kado J. Clinical significance of $\mathrm{nm} 23-\mathrm{H} 1$ proteins expressed on cell surface in non-Hodgkin's lymphoma. Leukemia 2003;17(1):196-202.

29. Muller W, Schneiders A, Hommel G, Gabbert HE. Expression of $\mathrm{nm} 23$ in gastric carcinoma: Association with tumor progression and poor prognosis. Cancer 1998;83(12):2481-2487.

30. Szumilo J, Skomra D, Chibowski D, Dabrowski A, Wallner G, Maciejewski R. Immunoexpression of $\mathrm{nm} 23$ in advanced esophageal squamous cell carcinoma. Folia Histochem Cytobiol 2002;40(4):377-380.

31. Masuda M, Kuratomi $Y$, Shiratsuchi H, Nakashima T, Naonobu $\mathrm{K}$, Komiyama S. Decreased CD44H expression in early-stage tongue carcinoma associates with late nodal metastases following interstitial brachytherapy. Head Neck 2000;22(7):662-665.

32. Gonzalez-Moles MA, Bravo M, Ruiz-Avila I, Esteban F, Rodriguez-Archilla A, Gonzalez-Moles S, Arias B. Adhesion molecule CD44 as a prognostic factor in tongue cancer. Anticancer Res 2003;23(6D):5197-5202.

33. Partin AW, Kattan MW, Subong EN, Walsh PC, Wojno KJ, Oesterling JE, Scardino PT, Pearson JD. Combination of prostatespecific antigen, clinical stage, and Gleason score to predict pathological stage of localized prostate cancer. A multi-institutional update. Jama 1997;277(18):1445-1451.

34. Etzioni R, Penson DF, Legler JM, di Tommaso D, Boer R, Gann $\mathrm{PH}$, Feuer EJ. Overdiagnosis due to prostate-specific antigen screening: Lessons from US prostate cancer incidence trends. J Natl Cancer Inst 2002;94(13):981-990.

35. Stamey TA, Johnstone IM, McNeal JE, Lu AY, Yemoto CM. Preoperative serum prostate specific antigen levels between 2 and $22 \mathrm{ng} / \mathrm{ml}$ correlate poorly with post-radical prostatectomy cancer morphology: Prostate specific antigen cure rates appear constant between 2 and $9 \mathrm{ng} / \mathrm{ml}$. J Urol 2002;167(1): 103-111.

36. Gleason DF, Mellinger GT. Prediction of prognosis for prostatic adenocarcinoma by combined histological grading and clinical staging. J Urol 1974;111(1):58-64.

37. Epstein JI, Pizov G, Walsh PC. Correlation of pathologic findings with progression after radical retropubic prostatectomy. Cancer 1993;71(11):3582-3593.

38. Schroder FH, van der Cruijsen-Koeter I, de Koning HJ, Vis AN, Hoedemaeker RF, Kranse R. Prostate cancer detection at low prostate specific antigen. J Urol 2000;163(3):806-812.

39. Zincke H, Oesterling JE, Blute ML, Bergstralh EJ, Myers RP, Barrett DM. Long-term (15 years) results after radical prostatectomy for clinically localized (stage T2c or lower) prostate cancer. J Urol 1994;152(5 Pt 2):1850-1857.

40. Han M, Partin AW, Pound CR, Epstein JI, Walsh PC. Long-term biochemical disease-free and cancer-specific survival following anatomic radical retropubic prostatectomy. The 15-year Johns Hopkins experience. Urol Clin North Am 2001;28(3):555-565.

41. Roberts SG, Blute ML, Bergstralh EJ, Slezak JM, Zincke H. PSA doubling time as a predictor of clinical progression after biochemical failure following radical prostatectomy for prostate cancer. Mayo Clin Proc 2001;76(6):576-581.

42. Pettaway CA. Prognostic markers in clinically localized prostate cancer. Tech Urol 1998;4(1):35-42.

43. Blute ML, Bergstralh EJ, Iocca A, Scherer B, Zincke H. Use of Gleason score, prostate specific antigen, seminal vesicle and margin status to predict biochemical failure after radical prostatectomy. J Urol 2001;165(1):119-125. 